\title{
Examining Cultural and Technological Change: A Study of Cultural Affordances on WeChat
}

\author{
Yinan SUN \\ University of Hawai i at Manoa \\ sunyinan@hawaii.edu
}

\author{
Daniel D. Suthers \\ University of Hawai i at Manoa \\ suthers@hawaii.edu
}

\begin{abstract}
This study presents qualitative research of the interaction among WeChat, users, and Chinese culture by applying a three-dimensional notion of cultural affordances. The data is collected by conducting 10 semi-structured in-depth interviews, follow-up discussions, and observations, and is analyzed via the grounded theory approach. The study provides preliminary findings that demonstrate the roles of WeChat, users, and Chinese culture in terms of cultural and technological changes. The study also discusses the interactive patterns among three dimensions of cultural affordances and offers possible direction for further study.
\end{abstract}

\section{Introduction}

Launched in January 2011 by Tencent, WeChat is considered to be one of the most important mobile applications in China [27, 45, 48, 56]. As of the third quarter of 2018, WeChat monthly active users reached 1.08 billion [29]. The average user spent 139 minutes each on WeChat and 68 million videos were posted on a daily basis in 2017 [45, 58].

Due to its popularity in Chinese society, more and more researchers start to investigate $\mathrm{WeChat}$. In general, prior studies on WeChat can be divided into six main categories: 1) users' motivations of WeChat usage, 2) detrimental aspects of WeChat usage with a focus on mental health, 3) the social influence of WeChat, 4) users' behaviors on WeChat (e.g., voting, or liking), 5) discontinuance of using WeChat, and 6) the design of WeChat. Prior research is crucial in terms of understanding WeChat. Yet, prior studies make light of the cultural aspect when investigating these issues.

To elaborate, prior study demonstrates the factors that affect WeChat users' motivations and practices include: relax and stress relief $[19,42,71]$, influences of friends [40], entertainment [20,35,48], information [20, 35], sociality [35, 44, 48, 74], trust [35], social support $[19,49,64]$, social values [71], fashion [48], age [20,
69], gender [20,69], and social and economic status [44, 70]. In terms of users' behaviors on WeChat, prior studies show that female users spend more time on WeChat, yet they are less enthusiastic about interpersonal communication on WeChat [48]. Men and older people show more empathy, and they are more likely to vote on WeChat based on reciprocity and intimacy [69]. Positive emotions play a positive role in terms of liking behaviors on WeChat [44, 74]. In addition, the fear of missing out and online social anxiety led users to make positive self-presentation and expect positive feedback from others [17]. Meanwhile, people who overuse WeChat tend to believe in destiny or fate and they are more likely have high-level stress and other behavior problems $[25,75]$. Yet, the study on cultural aspect of users' motivations for and ways of using WeChat is missing.

Equally important, prior studies on the design of WeChat examine the technological, psychological and social aspects of the platform while overlooking the cultural aspect. For example, Peng [51] contends that WeChat follows attentive design that seeks to keep Chinese youth's constant attention toward the platform through features like "the red dot" that indicates new messages. Chen, Mao, and Qiu [13] maintain that WeChat is "probably the world's most outstanding case of sticky design" (p. 11). Compared to other social media platforms, WeChat has similar functions, such as peer-to-peer texting, video and picture posting, group chatting, newsfeed, mobile games, and liking or voting mechanism [45]. However, WeChat is unique in many ways [45]. For example, one has to provide a cellphone number that is registered under a national ID to access certain functions, such as WeChat Pay or city services (e.g., paying electricity bills, making an apportionment with a public hospital). In addition, WeChat does not intend to cultivate a virtual world that is completely different from the real world [71]. Instead, users on WeChat have high familiarity with their real-life contacts since "most WeChat friends know each other in the reality" [19, 45]. Additionally, WeChat allows users to send digital red envelopes since 2014 [64]. Prior 
research on WeChat design is illuminating. Yet, the uniqueness of WeChat associated with Chinese culture is still poorly understood.

In general, prior research shows that the design of a social media platform and the motivations and ways of using it are heavily affected by culture [33, 53]. In reverse, the features of social media platforms could maintain certain cultures as well as form new ones [4, $16,23]$. Yet, prior research falls short of explaining how Chinese culture affects the design and ways of using WeChat as well as how WeChat affects Chinese culture in return. To further develop this understanding, this research seeks to examine the interaction among Chinese culture, WeChat, and WeChat users. To elaborate, this research attempts to investigate: 1) how features of WeChat affect Chinese culture and users in terms of their ways of doing and thinking, 2) how WeChat users affect the design of WeChat and Chinese culture, and 3) how Chinese culture affects the design and ways of using WeChat.

\section{Theoretical Framework}

To address the research questions, this paper employs a novel definition of cultural affordances as its theoretical framework. Coined by American psychologist James Gibson [21], the concept of affordances is described as "the affordances of the environment are what it offers the animal, what it provides or furnishes, either for good or ill" (p. 127). Scholars in the field of social media studies apply the notion of affordance to investigate what a social media platform offers to its users and related effects. Yet, those studies primarily focus on the technological aspect of an affordance. Later, the notion of cultural affordances is proposed to examine the cultural aspect of technology and how culture can affect users' ways of using technology $[15,54,61]$.

Nonetheless, the prior understanding of cultural affordances is insufficient to analyze the dynamic interaction among technology, culture, and users in a holistic way. These research focus on how established cultural values affect ways of using technology without discussing how technology and users can affect culture in return. For example, Turner and Turner [61] state that cultural affordances are features that are based on the objectified and historically developed meanings and values. Costall [15] suggests that canonical affordances of an object refer to its particular normative meanings. Hence, the literature about the interaction between technology and culture is still partial and incomplete. To respond to this theoretical vacuum, we offer a novel definition of cultural affordances that contains three dimensions to assemble culture, technology, and users in a holistic way.
The new definition of cultural affordances includes cultural affordances of technology, cultural affordances of users, and affordances of the cultural. Before diving into details, we need to clarify several issues. Firstly, it is important to point out that affordances are potentials for action rather than deterministic causes for action. An entity, including human and non-human actors, can choose to either take up these potentials or not. Hence, this entity has agency or is an agent. Agency is defined as acting upon oneself rather than upon others in this research. This is how agency is different from affordances that can potentially influence other actors or agents. Equally important, we understand culture as a set of complex connections, including established and emerging values and practices [3].

The dimension of cultural affordances of technology is what technology as a particular environment can offer to users to either reinforce established cultural values and practice or to destabilize them by cultivating new ones: it is contingent and contextual. Cultural affordances of technology recognize the agency of users and culture. For example, the feature of digital envelope of WeChat allows users to practice the culture of guanxi/interpersonal relationships [25]. The dimension of cultural affordances of users is what a user can offer to other users, technology, and culture: it showcases how users utilize, negotiate with, affect other users, technology, as well as certain cultural values or practice. The dimension of cultural affordances of users acknowledges the agency of technology and culture: we argue that anything users post, like, or comment is what they offer to technology and culture (as the environment of users). These activities do not have to be something big; instead, the minimal actions that users take can invite other users, technology, or culture to take actions upon oneself to respond what is offered. For example, users use seemingly consenting emojis to express dissent on WeChat [76]. The dimension of affordances of the cultural is what a cultural value or practice can provide to affect individuals' ways of doing and thinking, including ways of designing and using technology: it recognizes the agency of technology and users. The affordances of the cultural explores invisible and ambient culture: like a fish coming to understand that it lives in water, it pays attention to collective ways of doing and thinking that we take for granted, reveals the unnoticed and the sub-consciousness or unconsciousness, and identifies looming norms as well as the unknown. For example, filial piety affects Chinese students' ways of using WeChat [12].

In this empirical study, we examined the dynamic interaction among WeChat, users, and Chinese culture by applying the three dimensions of cultural affordances, respectively: what $\mathrm{WeChat}$ can offer to users and Chinese culture, what users can offer to WeChat and 
Chinese culture, and what Chinese culture can offer in terms of the design of and ways of using WeChat. It should be noted that providing a final explanation of Chinese culture or users' practices on WeChat goes beyond the scope of cultural affordances. Instead, cultural affordances are utilized to explore the ongoing interaction among ordinary people, technology, and culture.

\section{Methods}

Data gathering took place from June to August 2020 and included 10 in-depth, semi-structured interviews with WeChat users in China. We recruited the participants through a combination of purposive and snowball sampling. Our study was approved by the institutional review board (IRB) at University of Hawaii at Manoa. The participants came from both Southern and Northern China. This study selected five participants from Northern China (e.g., Beijing, Shanxi province, Hebei province) and five participants from Southern China (e.g., Zhejiang province, Hubei Province). The age of our participants ranged from 25 to 45 years old. There were 4 men and 6 women. Our criteria of recruiting participants were having the experience of using WeChat and an interest in Chinese culture. All interviews were conducted by the first author via WeChat video chat due to the outbreak of COVID-19. All interviews took place in Mandarin, and each interview was 60-90 minutes long. During the interview, participants were asked for some background information, including age, occupation, years of using WeChat, and daily hours of using WeChat, and then were asked the role of $\mathrm{WeChat}$ in their lives, the effect of WeChat on their ways of living, and other related questions. After the interview, follow-up discussion sessions were conducted to clarify and confirm related information. Each discussion session was 45-60 minutes long. We also observed participants' posts on WeChat. During the interview, the first author took notes and kept audio recordings. These recordings were transcribed in Mandarin and then translated to English for analysis. After all transcriptions were imported into NVivo, we analyzed the data using the techniques of grounded theory as defined by Charmaz $[7,59]$. To be specific, our analysis began with "initial coding," in which we assigned short phrases as codes. The first round of coding was done line-by-line within transcripts, so that codes stayed close to data and remained open. Examples of first-level codes included "WeChat is an essential tool", "adding someone only out of politeness", and "avoid using audio messages in a professional context". Then, we proceeded to analyze the initial codes by focusing on the most frequent or significant ones that can respond the research questions. Second-level categories included "WeChat keeps family members closer", "blocking friends who do not share the similar worldview", and "do not like to see posts that are for showing off wealth". Later, we conducted theoretical coding to extract themes for a conceptual understanding and identify the relationships among different themes. The third-level themes include "certain traditional values are strengthened on WeChat", "Chinese cultural values affect users' ways of using WeChat", and "younger generation is leaving WeChat". The process of analyzing data was iterative - we continuously went back and forth among categories, themes, and data to discover patterns and subject data to further scrutiny. Finally, we arrived at distinct themes that highlight how WeChat, users, and Chinese culture interact.

\section{Preliminary Findings}

Findings from this initial sample, reported below, will inform the next step of our research with an expanded sample.

\subsection{Cultural Affordances of WeChat}

\subsubsection{Guanxi Culture is Strengthened}

Guanxi is a crucial cultural phenomenon in Chinese society [10]. It is understood as an individual's social connections or social ties [22, 39]. In general, guanxi can be categorized into three types, which are expressive ties, instrumental ties, and mixed ties [34]. An expressive connection exists among family members or close friends. An instrumental connection happens when someone needs to achieve an instrumental goal. For instance, a passenger pays a taxi driver to get to a destination. A mixed connection occurs when people have some level of trust or affection with an instrumental goal in mind. For example, a person maintains a good relationship with his/her neighbor, and later this person asks the neighbor to check on the apartment when he/she is away. In return, the neighbor does not require any financial reward. Instead, the neighbor expects the same level of help in the future.

All participants expressed that their guanxi have been strengthened and increased by using functions of WeChat, such as WeChat group, QR code, and Moments where users can post, read, like, and comment on other people's posts. It is important to point out that participants do not only interact more with their direct family members or close friends, but also with their extended family members, high school classmates, acquaintances, and random people (e.g., a flower seller) with whom they previously communicated less or did not maintain contacts with at all. Consequently, their social relations are increased in terms of the number of their contacts as well as strengthened in terms of the 
depth of their communication. For instance, when the researcher asked about ways of using WeChat, a participant stated:

I used WeChat to stay in touch with my families every day. I guess that every Chinese must have a WeChat group that includes all his/her family members, including both direct family members and extended family members, such as aunts, uncles, cousins who might live in other cities. In the morning, I normally receive some greetings from other family members, the weather forecast, and messages that remind me to add more clothes if the weather is bad, or some social news on that day. I normally share my child's pictures or videos in the family WeChat group, especially during the pandemic.

Another participant expressed that WeChat provides her the opportunity to reconnect with her high school friends:

I have three good friends in high school. If I missed them, I had to call them one by one back then. It is also hard to find the time to get together as we live in different cities. Now, we created our own We Chat group, and the four of us can talk to each other together either through video calls or text messages. So, we feel that we are still very close to each other.

Equally important, our research finds that WeChat can provide users the opportunity to maintain contacts with random people for instrumental needs and transform a one-time interaction into a long-term relation. For example, a participant shared that she randomly found a flower shop that she likes. Later, she added the owner on her WeChat list, "I can see the posts of this owner on WeChat, and I find he works very hard. So, I feel that I can trust him. I always book flowers from him since then." It can be said that trust plays an important role in terms of creating and maintaining a social tie even though it is only for an instrumental purpose. Being able to read other users' posts on WeChat provides the chance of increasing trust among random people to further bonding a relationship. Similarly, another participant described his experience with a vegetable seller during the outbreak of COVID19:

We cannot go out to buy food. People living in the same building created a WeChat group to help each other. Someone invites a vegetable seller to join in our WeChat group. Later, I added him on my WeChat list, and order stuff with him when I am busy.

In addition, the participant expressed that when using WeChat group to communicate with this vegetable seller, other team members can be his witness if the seller has any dishonest conduct. Hence, it can be said that using WeChat group can increase trust among strangers. Due to the increasingly fast of the pace of life in modern China, people have less time to spend with their families or neighbors, or on meeting new people. Hence, it can be said that WeChat offers users' an opportunity to strengthen and increase one's social connections.

The design of WeChat plays an important role in terms of strengthening guanxi culture. A user needs a mobile phone number to register WeChat. Once WeChat is installed on a phone, the default setting allows a user to automatically add friends if he/she has their phone numbers. Consequently, many existing social connections are re-established on WeChat.

\subsubsection{Occupational Hierarchy as Culture is Destabilized}

People are traditionally separated into four social classes based on occupations, which are shi as scholars, nong as farmers, gong as workers, and shang as businessmen [18]. This occupation classification is associated with the hierarchical system of Confucianism that can be traced back to late Zhou dynasty [18]. It is important to point out that the four occupations are separated based on Confucian beliefs rather than one's socioeconomic status. In other words, scholars as an occupation have higher reputation than businessmen even though the businessmen could make more money. Even though the occupational classification was tremendously increased in modern China, prior research shows that occupation still matters, and people are more likely to associate with others within the same occupation [5].

In contrast with prior research, our findings show that WeChat destabilizes the occupational class and its related cultural values. For example, a participant, who has a master's degree, shared that he and his fitness coach became friends as they can maintain their communication and see each other's life through WeChat after the fitness coach left for another gym. All participants mentioned that they maintain contacts with people from different occupations. For example, a participant explained:

On my WeChat friends' list, there are people who I met randomly, such as couriers, real estate agents, people who run micro business on WeChat. ... I did not know what a courier's life looks like before, and now I feel like I became more considerate as I know his life is not easy.

Whether intentional or not, users learn more about people who come from other occupations through Moments on WeChat. In doing so, the traditional occupation hierarchy has been destabilized as WeChat 
provides users the opportunity to demonstrate different aspects of their lives and it is accessible to his/her followers.

\subsubsection{Simplified Cultural Practices and Altered Cultural Values}

As a tradition, elders put money in red envelopes and give them to children and unmarried family members and wish them another healthy and safe year during Chinese Lunar Year [66]. People give red envelopes to express good wishes on many other occasions, such as weddings, birthdays, moving into a new apartment and other special anniversaries [41]. As a replication of the real one, the digital red envelope is very successful: the total payment reaches to 400 million Chinese yuan (USD\$85 million) via 40 million messages during the 2014 Chinese Lunar New Year [24]. It can be stated that the feature of digital red packet allows a user to practice the established cultural values of filial piety and guanxi. Nonetheless, some participants expressed that the digital version lost its original meaning as the practice of giving red envelopes became more casual and the genuine affection had been altered with some instrumental purposes.

Likewise, people visit the graves of their ancestors to clean the surface and provide offerings on the Tombsweeping Day or Qingming Festival in early April each year [26]. In 2014, a tomb-sweeping service was offered on Taobao, a popular Chinese online shopping platform, to people who cannot visit the cemetery by themselves [2]. It raises immediate concerns about declining filial piety and commercialization of cultural values [2]. In 2017, a cemetery in Nanjing offered a similar service that allows people to hire staff to clean tombs and place offerings, and they can watch the ritual through a livestream on WeChat [1]. It seems that this service became gradually acceptable. According to Shanghai Civil Affairs Bureau, 2.19 million people used cloud tomb-sweeping services in 2019 [26]. Due to the outbreak of COVID-19, around 30 cities in China start to offer "cloud tomb-sweeping" services by utilizing WeChat live broadcast [26]. Nonetheless, some participants expressed that they would never use this service, "I have to go there by myself, I will never pay for this. It totally misses the point."

\subsubsection{Emerging Culture on WeChat: An Emphasis on Worldviews}

Our findings show that having similar worldviews plays a crucial role on WeChat. Users can share articles as well as express their opinions on their own Moments, which provides an opportunity to all users to identify people who do not share similar worldviews, life perspectives, or moral values. Consequently, users can take various actions from avoiding further communication, turning off this person's Moments, or blocking him/her completely on WeChat.

When asking participants how WeChat affected their communications with others, participants mentioned that they use the posts on Moments as a crucial factor to decide to what extent they would associate with a person or whether they want to keep this person on their WeChat. For example, a participant expressed that:

\section{My wife had an intense debate with her friend toward an article she posted on her Moments. Later, my wife got tired of the debate and blocked this friend who she knew for a long time. Another friend of mine told me that Moments is like his personal backyard. He welcomes anyone to visit this virtual space. Yet, he finds it is disrespectful or even assaulting if someone left negative comments.}

Indeed, WeChat Moments provides a platform to demonstrate a person's opinion or lifestyle. Based on the posts, users can have a general impression in terms of a person's worldviews or values. Particularly, when there is a social issue that causes controversial discussions, users can find people who are either likeminded or are in the opposite side. It can be said that the worldview becomes a salient factor to bond social ties on WeChat. Consequently, it may affect users' social tie in reality.

\subsection{Cultural Affordances of WeChat Users}

\subsubsection{Users' Feedbacks and WeChat Design}

The feature of Moments on WeChat offers three levels of privacy control to users, which are the contact level, the post level, and the temporal level [28]. It is important to point out that these privacy settings have been improved a couple of times. For example, in April 2012, Moments was first launched without the temporal control. Users can only close their Moments if they want to hide their posts. Due to users' privacy concerns, a new temporal control offered three options for timelimiting posts (last three days, last month, and last six months) [47]. In addition, our findings show that users require WeChat to listen to users' feedbacks more when developing new functions. For example, a participant expressed that he noticed WeChat changed its privacy setting on WeChat Moments several times, "I once left comments on WeChat official account to complain about the privacy settings on Moments as it only has two options. ...I hope WeChat can listen to more users' feedbacks." Another participant suggests WeChat should provide more culture-friendly design to elder users, "my mother has a hard time to find the button of voice call. I found out that the sign of plus or '+', which means more functions, does not make sense to her." 


\subsubsection{Younger Users Spend Less Time on WeChat}

Our finding resonates with prior reports that the younger users (e.g., college students, users who are 25 years old or younger) prefer QQ rather than WeChat due to anxiety and peer pressure. Developed by Tencent in 1999, QQ is an internet-based instant messaging platform that offers many features, such as QQ Games, QQ Mail, and Q Zone [72]. Different from WeChat, users can register a QQ ID by using an email address without a mobile phone number [50]. Hence, it can be argued that QQ provides users more privacy in terms of users' real identity. Thus, it provides them more space to express themselves without worrying about being criticized by their parents or colleagues. In contrast, younger users feel that they are monitored by their parents or supervisors on WeChat $[8,9]$. One participant mentioned that his/her daughter spent more time on QQ, and mainly uses WeChat to communicate with her family members, "I did not know her QQ ID, so I did not know how she would behave on QQ." Another participant points out that it is easier to look for people who share overlapping interests on QQ by using search interest groups on QQ. In contrast, WeChat does not support this kind of search unless one knows the precise name of that WeChat group. It can be said that QQ is more useful for younger users who still explore their hobbies.

\subsubsection{Bottom-up Communication on WeChat}

When there is a discrepancy between an authority and ordinary people, users sometimes choose to take initiative to express their own opinions via WeChat. Consequently, the authority may change its original attitude based on users' posts on WeChat. For example, $\mathrm{Ma}$ [40] states that WeChat users utilize screenshots to express dissent towards the treatment of two doctors during the beginning of COVID-19: eventually, the local government apologized, and the articles about these two doctors could later be found online. Our findings resonate this argument. One user expressed that:

I can tell there is a change of attitude from the authority between 1 to 3 am and after 3 am in the morning on that day. From 1 to 3 am, the posts about this doctor on WeChat had been deleted repeatedly and users kept posting it. After 3 am, one can tell that the opinion becomes unanimous. It is like a dialogue that is mediated through WeChat among users and the officials.

Similarly, another participant shares that Moment on WeChat provides a public space to individual users to participate in social discussions, "I normally do not post articles to express my personal opinion on Moments. But on that day, I cannot help posting to express my support to the doctor. It is a voice from the bottom." It is worth noting that two dimensions of cultural affordances are involved in this case: what the feature of Moment offers and what users offer work together and eventually change the mainstream attitude towards a social accident and its related cultural value and practice.

\subsection{Affordances of the Cultural on WeChat}

\subsubsection{The Culture of Self-Discipline/Self-Regulation}

Self-cultivation is essential in Confucianism [37, 60]. Self-regulation or self-discipline is the way towards self-cultivation [60]. Rather than an abstract concept, Confucian moral philosophy offers specific ways for practicing self-regulation [67]. For example, Confucius advises that a person should not show off one's wealth or be materialistic since it would let this person stand out and cause disharmony, and one should be circumspect about one's speech and conducts as a practice of self-regulation even when he is alone [36, 38, $63,65]$.

Our findings show that the principle of selfregulation or self-discipline still affects ways of using WeChat. When users were asked about what kinds of practices on WeChat make them uncomfortable, several common issues are mentioned by all participants. Firstly, a WeChat user is more likely blocked if he/she posts pictures for showing off. One participant expressed that

I used to have someone on my WeChat like to show off. When he/she posts a picture, it is very easy to tell that what he/she really wants to show is the logo of his/her new expensive car. Later, I blocked him/her since I did not want to associate with people like him/her.

Not only showing off wealth, but also other types of showing-off practices are not welcome either, such as posting one's child pictures/videos more than once a day or posting a series of videos (normally 10-second-long) while traveling. Participants find these kinds of practices on WeChat annoying, and they may later choose to hide this person's posts on the Friend's Circle or even block this person. In contrast, several participants explained that they always pay attention to what kind of contents they post and how frequent they post on WeChat. All participants expressed that they follow the principle of keeping a low profile on $\mathrm{WeChat}$. For example, a participant stated that:

I like to post it on WeChat when I travel. But I do not post more than once a day, otherwise I am worried that other people may find that I am showing off.

In addition, participants stated that there are two functions on WeChat that they rarely used since it is against their moral values. The two functions are Shake \& Shake and Drift Bottle. As a way of meeting strangers 
and making friends, Shake $\&$ Shake allows two or more users to match up if they shake their phones at the same time [68]. Similarly, Drift Bottle is a function that lets users meet strangers and become pen friends through opening a virtual drift bottle and reading messages from strangers on WeChat. Most participants expressed that they never used the two features as they heard that people use them to look for casual sexual relations. One user did try it once out of curiosity:

I randomly open the Shake \& Shake on my phone. I was not sure what it was used for and kind of curious. When I shook my phone, I got a couple of greetings from strangers immediately. However, the languages were vulgar for me.

In 2018, the popular function of Drift Bottle is suspended as Tencent "discovered through user complaints and media reports that the drift bottle function was used to disseminate pornography and solicit prostitutes" [6]. It can be argued that two dimensions of cultural affordances, which are cultural affordances of users and affordance of the cultural, affect what WeChat can offer in return.

\subsubsection{The Culture of Harmony}

Harmony is an essential concept in Confucianism that is deeply rooted in Chinese culture [57]. It includes three elements, which are harmonious relationships with others, the unity of humans and nature, and the practices of Middle Way or avoiding extreme conduct [57]. It can be argued that maintaining harmonious relationships with others is the most crucial one in the relationoriented Chinese society. Specifically, to protect harmonious relationships with others, one should not complain about others publicly since it may make this person lose face [32]. Additionally, when making a comment, one should leave some space for ambiguity rather than providing an absolute right or wrong judgment as the context may change [12]. Equally important, one needs to follow the social/institutional hierarchy to maintain a harmonious relationship, such as between children and parents, students and teachers, and subordinates and leaders [14,73].

Our findings reveal that the concept of harmony affects users' way of using WeChat. For example, the design of WeChat allows a user to add someone quickly either via a QR code, a phone number, or a WeChat ID [13]. Participants expressed that it is very hard to refuse someone's WeChat invitation even though sometimes they do not want to accept, particularly in a face-to-face context. Put differently, refusing someone's invitation on WeChat may make the invitee lose face and disturb the harmonious relationship between the two. In addition, participants rarely leave negative comments or challenging questions on other people's posts to protect the harmonious relationship. Likewise, they restrained themselves from posting anything that might be controversial or negative (e.g., complain). For instance, when asking what kinds of practices that they are less likely to conduct on WeChat, one participant explained that:

One should try to avoid posting anything that may cause a debate with your friends on WeChat. You can discuss these controversial issues in person. Yet, it is hard to fully explain yourself on WeChat. Hence, I'd rather avoid.

Another participant stated that:

During the MeToo movement in 2018, I had several intense debates with my friends on WeChat. I just said whatever came to my mind right away under that friend's post. But I won't do it anymore. I am trying to use a way to express my opinion as well as make others feel comfortable. If I really disagree with someone, I will leave a private message to this person rather than leave comments directly under his post since our common friends may see it.

Indeed, what WeChat offers could affect the way of expressing one's opinion. So does a cultural value. In this case, what the cultural value of harmony offers eventually affects this participant's way of using WeChat. Additionally, our findings show that there are ways of showing respect to authorities on WeChat. For example, users mentioned that they do not use voice messages to communicate with supervisors. Instead, they write messages in a concise and respectful manner while avoiding using casual language, emoji or misspelling. Most participants claimed that the nature of a subordinate-supervisor relationship does not change even though one can add each other on WeChat: "you may be able to see a bit more about his personal life or know the nickname of your boss on social media. However, it won't change the fact that he is still your boss."

\subsubsection{Gender Culture on WeChat}

Prior research claims that in modern China, particularly in large cities like Shanghai, Guangzhou, or Beijing, younger women are more influenced by Western values, whereas the older generation is still influenced by traditional Chinese values and practices $[30,31]$. Nonetheless, our research presents a different aspect of the narrative. Female participants mentioned that they chose not to post contents that might be against their images as mothers. For example, one participant shared with us that she never posted anything about a music band she really likes, "my posts are open to all my followers, including my parents-in-law. I did not want to hide anything from anyone. ...I really like a music band, but I am afraid what my mother-in-law 
might not be pleased if she saw I posted a handsome singer who is much younger than me." Likewise, another participant mentioned that she was worried whenever she posted anything about her pet, "I treat my pet as my child, but I did not know how my parents and parents-in-law react to that. I guess that they might think I should have a child instead of treating my pet as my child. ... but I did not block them since it is too complicated for me." It can be argued that the ways that women who live in large cities use WeChat are still affected by traditional values in terms of their gender role. Additionally, the culture of filial piety can indirectly affect their ways of using WeChat as well.

\section{Discussion}

As shown in the preliminary findings, what the cultural affordances of WeChat offer include strengthening, destabilizing, altering, and fostering various cultural values and practices. For example, the culture of guanxi is strengthened through the features of WeChat Group, Moments, and the design of WeChat that allows users to add a new contact through multiple convenient ways. In contrast, the occupational hierarchy is destabilized since users can easily access the lives of people from different occupations via Moments. The feature of digital red envelope on WeChat not only alters the traditional cultural practices of giving red envelopes but also its cultural values and replaces it with a culture of convenience and casualness. Additionally, WeChat fosters a culture that emphasizes similar worldviews.

The cultural affordances of WeChat users include their feedbacks, posts, and ways of using/disusing WeChat; and it can cause changes to the design of WeChat, sustain certain cultural practices and values, and affect authorities' attitude towards social issues. Users invent their own ways of using WeChat regardless the intentions of the designer, or disuse certain features if it is against their own values. What Chinese cultural values and practices can offer are guidance in terms of using and designing WeChat. It is worth noting that multiple cultural values and practices can add together to affect ways of using and designing WeChat. For example, the culture of self-regulation and harmony can both be the reasons of not leaving a negative comment on WeChat. Additionally, the feature of Moments can strengthen guanxi culture and weaken the value of occupational hierarchy simultaneously. These examples suggest that it will be problematic if we look for a fixed or final explanation to define any cultural or technological phenomenon. The theory of cultural affordances does not directly provide the explanations, but instead can be used as a tool to delineate the interactive patterns among WeChat, users, and Chinese culture. Equally important, prior studies show that
Chinese cultural attributes are inherent in the design of WeChat $[46,62]$. Due to the limitation of resources, we did not include WeChat designers as part of the research but are seeking access in the future.

In terms of the three dimensions of cultural affordances, our preliminary findings show that they are more likely to interact with each other simultaneously rather than following a certain sequence. It can be argued that Chinese cultural values and practices can hugely affect the design and ways of using WeChat. Hence, it can be said that the more cultural attributes are embedded in a technological platform, the greater chance that it will be accepted by users. Nonetheless, when cultural affordances of technology are against affordances of the cultural, cultural affordances of users can play an essential role to influence and sustain the interaction among the two. Further research should be conducted to provide more detailed examples.

\section{Implications, Limitations, and Future Research}

This research deepens the understanding of cultural affordances by applying the notion to WeChat, demonstrating that the interaction among WeChat, users, and Chinese culture is a multidirectional simultaneous process rather than a unidirectional movement in a particular order. The study has a number of limitations. Firstly, the findings cannot be presumed to generalize to a larger population due to the limited number of participants. However, it helps us to test the applicability of cultural affordances to WeChat, formulate a basis in terms of understanding how WeChat, users, and Chinese culture interact, and prepare for the further research that will include WeChat designers and more younger participants. Secondly, the study only focuses on WeChat and Chinese culture: care should be taken when generalizing findings to other countries and other social media platforms. As this is the very first research applying the three-dimensional definition of cultural affordances to WeChat, we chose a small sample size to test and explore its application. Even though the findings are preliminary, it contributes to expand our understanding of how one can utilize the notion of affordances to examine the interaction among culture, technology, and individual users. Further research with a larger sample size and WeChat designers will be conducted in the future.

\section{References}

[1] Ancient Chinese tomb-sweeping festival goes hi-tech. (2017, April 4). BBC News. https://www.bbc.com/news/world-asia-39487437. 
[2] Assche, S. V. (2014, April 1). You can hire someone to sweep your ancestors' tombs on Taobao. That's Online. https://www.thatsmags.com/china/post/4186/taobao-offerstomb-sweeping-by-proxy-services.

[3] Barker, C. (2016). Cultural studies: Theory and practice (5th edition). SAGE.

[4] Bertot, J. C., Jaeger, P. T., \& Grimes, J. M. (2010). Using ICTs to create a culture of transparency: E-government and social media as openness and anti-corruption tools for societies. Government information quarterly, 27(3), 264-271. [5] Bian, Y., Breiger, R., Galaskiewicz, J., \& Davis, D. (2005). Occupation, class, and social networks in urban China. Social forces, 83(4), 1443-1468.

[6] Borak, M. (2018, December 5). Tech in Asia - Connecting Asia's startup ecosystem. https://www.techinasia.com/wechatsuspending-favorite-features-people-sell-porn.

[7] Charmaz, K. (2006). Constructing grounded theory: A practical guide through qualitative analysis. Sage.

[8] Chen, C., \& Qu, T. (2019, August 24). Chinese teens are shunning WeChat posts to avoid prying parents. South China Morning Post. https://www.scmp.com/tech/appssocial/article/3024156/chinese-teens-are-shying-away-

posting-about-their-lives-wechat.

[9] Chen, L. (2018, July 24). Why China's tech-savvy millennials are quitting WeChat. South China Morning Post. https:/wwwscomp.com/news/china/society/article/2156297/how-growingprivacyfears-chinarare-driving-wechat-users-away.

[10] Chen, L.S., Goh, C. F., Yifan, S., \& Rasli, A. (2017). Integrating guanxi into technology acceptance: An empirical investigation of WeChat. Telematics and Informatics, 34(7), 1125-1142.

[11] Chen, M. J. (2002). Transcending paradox: The Chinese "middle way" perspective. Asia Pacific Journal of Management, 19(2), 179-199.

[12] Chen, S. (2018). Face, Social Ties and Positive Energy: an analysis of young Chinese WeChat users' reflections on mediated social relations.

[13] Chen, Y., Mao, Z., \& Qiu, J. L. (2018). Super-sticky WeChat and Chinese society. Emerald Group Publishing.

[14] Chuang, Y. C. (2005). Effects of interaction pattern on family harmony and well-being: Test of interpersonal theory, Relational-Models theory, and Confucian ethics. Asian journal of social psychology, 8(3), 272-291.

[15] Costall, A. (2012). Canonical affordances in context. AVANT. Pismo Awangardy Filozoficzno-Naukowej, (2), 85-93) [16] Duan, J., \& Dholakia, N. (2015). The reshaping of Chinese consumer values in the social media era exploring the impact of Weibo. Qualitative Market Research: an International Journal, 18(4), 409-426.

[17] Duan, W., He, C., \& Tang, X. (2020). Why Do People Browse and Post on WeChat Moments? Relationships among Fear of Missing Out, Strategic Self-Presentation, and Online Social Anxiety. Cyberpsychology, Behavior, and Social Networking, 23(10), 708-714.

[18] Fairbank, J. K., \& Goldman, M. (2006). China. Harvard University Press.

[19] Gan, C. (2017). Understanding WeChat users' liking behavior: An empirical study in China. Computers in Human Behavior, 68, 30-39.

[20] Gan, C., \& Li, H. (2017). Understanding the effects of gratifications on the continuance intention to use WeChat in
China: A perspective on uses and gratifications. Computers in Human Behavior, 78, 306-315.

[21] Gibson, J. (2011). The Ecological Approach to Visual Perception. 17th pr. New York: Psychology Press.

[22] Gold, T., Gold, T. B., Guthrie, D., \& Wank, D. (Eds.). (2002). Social connections in China: Institutions, culture, and the changing nature of guanxi (No. 21). Cambridge University Press.

[23] Hawn, C. (2009). Take two aspirin and tweet me in the morning: how Twitter, Facebook, and other social media are reshaping health care. Health affairs, 28(2), 361-368.

[24] Holmes, K., Balnaves, M., \& Wang, Y. (2015). Red Bags and WeChat (Wēixìn): Online collectivism during massive Chinese cultural events. Global Media Journal: Australian Edition, 9(1), 15-26.

[25] Hou, J., Ndasauka, Y., Jiang, Y., Ye, Z., Wang, Y., Yang, L., et al. (2017). Excessive use of WeChat, social interaction and locus of control among college students in China. PLoS One 12:e0183633.

[26] Hu, M. (2020, March 12). Amid virus, tomb-sweeping goes into the 'cloud'. archive.shine.cn. https://archive.shine.cn/metro/Amid-virus-tombsweepinggoes-into-the-cloud/shdaily.shtml.

[27] Huang, L. M., Zhu, Q. Y., Ding, J., \& Xu, C. J. (2014). Design and Realization of Technology Intelligence Push Based on WeChat. In Applied Mechanics and Materials (Vol. 631, pp. 1119-1122). Trans Tech Publications Ltd.

[28] Huang, X., Vitak, J., \& Tausczik, Y. (2020, April). " You Don't Have To Know My Past": How WeChat Moments Users Manage Their Evolving Self-Presentation. In Proceedings of the 2020 CHI Conference on Human Factors in Computing Systems (pp. 1-13).

[29] Iqbal, M. (2019, February 27) WeChat Revenue and Usage Statistics (2019). Business of Apps. Retrieved from https://www.businessofapps.com/data/wechat-statistics/

[30] Ji, Y. (2015). Between tradition and modernity: "Leftover" women in Shanghai. Journal of Marriage and Family, 77(5), 1057-1073.

[31] Kan, M. Y., \& He, G. (2018). Resource bargaining and gender display in housework and care work in modern China. Chinese Sociological Review, 50(2), 188-230.

[32] Keller, G. F., \& Kronstedt, C. R. (2005). Connecting Confucianism, communism, and the Chinese culture of commerce. The journal of language for international business, $16(1), 60$.

[33] Kim, Y., Sohn, D., \& Choi, S. M. (2011). Cultural difference in motivations for using social network sites: A comparative study of American and Korean college students. Computers in human behavior, 27(1), 365-372.

[34] Lee, D. J., Pae, J. H., \& Wong, Y. H. (2001). A model of close business relationships in China (guanxi). European journal of Marketing.

[35] Lien, C. H., \& Cao, Y. (2014). Examining WeChat users' motivations, trust, attitudes, and positive word-of-mouth: Evidence from China. Computers in human behavior,41,104111. [36] Liji. Book of Rites: Bilingual Edition. (2014). Dragon Reader. Kindle Edition.

[37] Little, R.: 2006, A Confucian-Daoist Millennium? (Connor Court Publishing, VIC).

[38] Low, K. P. (2013). Materialism, Confucianism and Confucian values. Educational research, 4(5), 4013-4412. 
[39] Luo, Y. (1997). Guanxi: Principles, philosophies, and implications. Human systems management, 16, 43-52.

[40] Ma, R. (2021). Graphic Activism on WeChat: The Aesthetics of Dissent in the Age of COVID-19. Design and Culture, 13(1), 33-42

[41] Mack, L. (2019, August 17). The Significance of Red Envelopes in Chinese Culture. ThoughtCo. Accessed March 5, 2020. https://www.thoughtco.com/chinese-new-year-redenvelope-687537.

[42] Mao, C. (2014). Friends and Relaxation: Key Factors of Undergraduate Students' WeChat Using. Creative Education, 2014.

[43] Martinsons, M. G., \& Ma, D. (2009). Sub-cultural differences in information ethics across China: focus on Chinese management generation gaps. Journal of the Association for Information Systems, 10(11), 2.

[44] Meng, B. (2020). When Anxious Mothers Meet Social Media: Wechat, Motherhood and the Imaginary of the Good Life. Javnost - The Public, 27(2), 171-185.

[45] Montag, C., Becker, B., \& Gan, C. (2018). The multipurpose application WeChat: a review on recent research. Frontiers in psychology, 9, 2247.

[46] Negro, G., Balbi, G., \& Bory, P. (2020). The path to WeChat: How Tencent's culture shaped the most popular Chinese app, 1998-2011. Global Media and Communication, 16(2), 208-226.

[47] $\mathrm{Ni}$ wufa zaidui haoyou chedi guanbi pengyouquan! Weixin shengjiban gaile yinsi shezhi quanxian [You cannot close your Moments completely! WeChat updates its privacy settings] (2017, March 28) 163.com. https:/www.163.com/news/article/CGL2BJ1M00018AOR.html

[48] Pang, H. (2016). Understanding key factors affecting young people's WeChat usage: an empirical study from uses and gratifications perspective. International Journal of Web Based Communities, 12(3), 262-278

[49] Pang, H. (2018). WeChat use is significantly correlated with college students' quality of friendships but not with perceived well-being. Heliyon, 4(11), e00967.

[50] Pang, K. (2021, March 18). How to use WeChat and QQ in China (2021). Wechat and QQ - How to use them in China (2019). https//www.chinahighlights.com/travelguide/article-qq.htm.

[51] Peng, Y. (2017). Affective networks: How WeChat enhances Tencent's digital business governance. Chinese Journal of Communication, 10(3), 264-278.

[52] Peng, Z. (2017). An examination of WeChat: Predictors of news use on a closed messaging platform. Michigan State University. Journalism.

[53] Pentina, I., Basmanova, O., \& Zhang, L. (2016). A crossnational study of Twitter users' motivations and continuance intentions. Journal of Marketing Communications, 22(1),36-55.

[54] Ramstead, M. J., Veissière, S. P., \& Kirmayer, L. J. (2016). Cultural affordances: scaffolding local worlds through shared intentionality and regimes of attention. Frontiers in Psychology, 7, 1090.

[55] Rose J, Jones M, Truex D. Socio-theoretic accounts of IS: The problem of agency[J]. Scandinavian Journal of Information Systems, 2005, 17(1): 8.

[56] Shen, C., \& Gong, H. (2019). Personal ties, group ties and latent ties: connecting network size to diversity and trust in the mobile social network WeChat. Asian Journal of Communication, 29(1), 18-34.
[57] Solé-Farràs, J. (2008). Harmony in contemporary new Confucianism and in socialism with Chinese characteristics. China Media Research, 4(4), 14-24.

[58] The 2017 WeChat Data Report. (2017, November 9). The Official WeChat Blog. Blog.wechat.com. hitps:/blogwechat.com/2017/11/09the-2017-wechat-datareport

[59] Thornberg, R., \& Charmaz, K. (2014). Grounded theory and theoretical coding. The SAGE handbook of qualitative data analysis, 5, 153-69.

[60] Tu, W. (1998). Humanity and self-cultivation: Essays in Confucian thought. Cheng \& Tsui.

[61] Turner, P., \& Turner, S. (2002). An affordance-based framework for CVE evaluation. In People and Computers XVI-Memorable Yet Invisible (pp. 89-103). Springer,London [62] Vodanovich, S., McKenna, B., \& Cai, W. (2017). Cultural values inherent in the design of social media platforms: A case study of WeChat.

[63] Wang, B. X., \& Chee, H. (2011). Chinese leadership. New York: Palgrave Macmillan.

[64] Wang, G., Zhang, W., \& Zeng, R. (2019). WeChat use intensity and social support: The moderating effect of motivators for WeChat use. Computers in Human Behavior, 91, 244-251.

[65] Wilson, E. (1900). The Wisdom of Confucius: With Critical and Biographical Sketches. Books, Incorporated.

[66] Wirth, K. (2017, January 25). What's the Significance of Lunar New Year Red Envelopes? Seattletimes.com. https://www.seattletimes.com/life/whats-the-significance-oflunar-new-year-red-envelopes/.

[67] Woods, P. R., \& Lamond, D. A. (2010, August). A Confucian Approach to Developing Ethical Self-Regulation In Management. In Academy of Management Proceedings (Vol. 2010, No. 1, pp. 1-6). Briarcliff Manor, NY 10510: Academy of Management.

[68] Yang, X., Sun, S. L., \& Lee, R. P. (2016). Microinnovation strategy: the case of WeChat. Asian Case Research Journal, 20(02), 401-427.

[69] Yanju, Z., Yu, Y., Chen, X., \& Xiongwei, Z. (2020). Guanxi or Justice? An Empirical Study of WeChat Voting. Journal of Business Ethics: JBE; Dordrecht, 164(1), 201-225. [70] Zani, B. (2020). WeChat, we sell, we feel: Chinese women's emotional petit capitalism. International Journal of Cultural Studies, 23, 803-820.

[71] Zhang, C. B., Li, Y. N., Wu, B., \& Li, D. J. (2017). How WeChat can retain users: Roles of network externalities, social interaction ties, and perceived values in building continuance intention. Computers in Human Behavior, 69, 284-293.

[72] Zhang, M. (2010). Tencent QQ.

[73] Zhang, Y. (1994). Confucianism and education/business: What the literature says.

[74] Zhao, H., \& Zhang, M. (2020). The Role of Guanxi and Positive Emotions in Predicting Users' Likelihood to Click the Like Button on WeChat. Frontiers in Psychology, 11. [75] Zhou, R., Hentschel, J., \& Kumar, N. (2017, May). Goodbye text, hello emoji: Mobile communication on WeChat in China. In Proceedings of the 2017 CHI conference on human factors in computing systems (pp 748759). [76] Zhou, X., and Wang, X. (2017). The relationship between self-control ability and WeChat addiction among university students. China J. Health Psychol. 8:037. 